\title{
Consumption Oriented Idol Worship in China
}

\author{
Xinyu Chen ${ }^{1, *}$
}

\author{
${ }^{1}$ University of Toledo, Toledo, Ohio, United States \\ ${ }^{*}$ Corresponding author. Email: xchen21@rockets.utoledo.edu
}

\begin{abstract}
Consumption Oriented Idol Worship in China introduces how "consumption-oriented idol worship" affects society in China. It defines consumption-oriented idol worship and describes how it is used in media and products to "throw them into ecstasy" and create a desire for possession. Along with these two points, it describes the three different forms of consumption-oriented idol worship: the "Idolization of Sentimental Capital," the "Idolization of Spiritual Capital," and the "Idolization of Ethical Capital." Also reviewed is how this affects society negatively, such as wasting. Especially noted is the lack of a true agenda for this trend and the lack of recognition from the Chinese government.
\end{abstract}

Keywords: Idol Worship, Chinese Fandom Marketing, Consumption, Social Media

\section{INTRODUCTION}

Idol worship has a great influence on the lives of teenagers in China. People aspire to be like their favourite idol stars and often mimic their style, activities, or relationships. The size of this subculture is alarming because it fails to show how much power these idols have over many people's lives. It can be compared to the obsession of many teenagers with their favourite celebrities. Idol worship is the worship of a particular celebrity, figure, or role model to the point that people conform their lives to fit his/her specifications. The idolworshipping subculture is much larger than it appears. There are several reasons given for this. The first reason is due to the release of many idols in China's entertainment industry, mainly dramas and movies, which influences teenagers' idol worship. This is what has caused the subculture to grow because more people are buying idols' products or watching their dramas or movies than before. The second reason for this subculture is because of how idols have received a lot of media exposure. The media has been giving more attention to the celebrities' private lives and to their popularity, both in China and abroad. This has boosted the marketing appeal to China's younger generation. The third reason idol-worshipping has grown is because of the idol's appearance. Chinese celebrities have many ways to attract the public's attention through fashion, hairstyle, and even through plastic surgery. Chinese idols would constantly change their appearances and try out new looks to gain attention and promote their image, like diffusion agents as Everett Rogers proposed about the
Diffusion of Innovations Theory [1]. Also, many celebrities promote their idol worship by attending various idol worship events. Finally, the growth of idol worshipping has made it easier for people to build idols and products around them, and more people were starting to cultivate their idols. This is also the cause of the idolworshipping subculture becoming so large because more idols appeared in China. Idol worshipping is a large market in China, especially among teenagers. Being a part of this idol-worshipping subculture can be very useful when it comes to promoting products, especially for idols. In China, the literacy rate is not that high. Using celebrities to sell products could increase sales because many people in China tend to trust celebrity endorsements more than ordinary people's advertisements.

Previous studies rarely pay attention to consumptionoriented idol worship in China, so this article mainly focuses on developing talent shows, the cause of popularity, and the relationship between the sponsor, idols, and fans. The process of these perspectives has become such consumption-oriented idol worship in China nowadays.

\section{CONSUMPTION ORIENTED IDOL WORSHIP IN CHINA}

\section{1. The development in china}

With the innovation of media and technology, the ways of living, learning, and entertainment are also adapting to these huge changes. Regarding entertainment, people are doing a variety of ways such as watching 
movies, reading books, playing video games, and so on. In addition to these mainstream amusements, various subcultures cultivated by small groups other than the mainstream culture have emerged. Among them, the most representative one is the current popular idol worship culture. The development of the entertainment industry in contemporary China is a typical prototype of this kind. The Chinese idol industry has been booming since Super Girl began airing in 2005. It was followed by Super Boy, The Voice of China, X-Fire and so on. These programs were broadcast on traditional media television stations, most of which could not be seen at any time due to the limitations of broadcasting time and space at that time. The programming is also subject to the approval and management of TV programs, and therefore cannot be presented in the audience's favourite way. In 2018, With the booming of mobile internet devices and the rise of mobile media, people can quickly grasp entertainment news and watch infotainment through mobile devices anytime and anywhere. This lifestyle change has also changed people's consumption habits, with more and more people no longer use cash for transactions and use online shopping as a normal part of their daily lives. The new generation is accustomed to Internet consumption and recreation. They are willing to pay time and money for their interests. Moreover, there are fewer restrictions on online shows compared to shows broadcasted on traditional entertainment platforms. Under this tendency, after learning from the successful experience of South Korean talent shows and seeing such a development trend, Chinese investment giants began to invest in the Internetbased entertainment industry, thus giving birth to two phenomenal idol talent shows "Idol Producer", a Chinese reality boy group survival show and "Produce 101 China", a spinoff from the South Korean franchise show Produce 101. Therefore, 2018 was dubbed "The genesis year of Idol." Since then, all kinds of talent shows have continued to develop, among which the "Produce" franchise of talent shows stand out in the same type of programs, become one of the most popular talent shows. The series of "Produce" programs are broadcast on the Tencent Video platform. Four talent shows have been held successively: "Produce 101", "Produce 2019", "Produce 2020," and "Produce 2021", and four idol teams have been successfully created: Rocket Girls 101, R1SE, BonBon Girls 303, and INTO1. The total viewership for the four shows was 5.572 billion, 4.162 billion, 8.421 billion, and 6.21 billion, respectively [2]. The series of "Produce" talent shows has gained significant attention and attracted many audiences' participation.

\section{2. idol worship impacts}

Talent shows after 2018 started a new stage of idol production. Empowered by technological development, fans, as idol followers and consumers, have changed from the traditional passive acceptance of the output of cultural products and concept value to active participation in the construction and operation of idols. And the relationship between fans and idols has been gradually reconstructed. For example, in the period of "Super Girl" in 2005, the dominant power of talent shows was mainly in the hands of the organizers, while the programming and flow direction of the shows were mainly controlled by TV stations and investors. This situation mainly lies in the fact that, limited by the communication technology at that time, the organizer could not receive feedback from fans immediately and could not interact in real-time. Since the show was broadcasted on TV stations, the program schedule also had to consider the factors of program censorship, so it could not be adjusted flexibly. This changed dramatically in 2018. The main difference is that various social platforms provide a platform like Weibo for fans to communicate with each other. The organizers can learn from and interact with fans on these platforms to adjust the real-time programming. In this case, the status of fans in idol shows has changed dramatically, from a passive audience to an indirect participant in program design [3].

In talent shows like Produce 101, trainees are alienated into commodities to be evaluated, analysed, and ranked. The reality of trainees being pushed into a competitive system where they are reduced to commodities comes from consumer-oriented idol worship. In a consumer-oriented industry, trainees and idols are not idols in the traditional sense of the word. Neither groups nor individuals in a group matter to the public. What matters is what they can do for consumers, both fans and the market who consume products and services created by idols. As capitals, they don't like to waste money on something consumers don't like, so it is important to know if an idol or a group can be liked by consumers (mainly fans) before investing in them. Thus, the overwhelming importance of the "merit" that trainees or idols who are seen by fans would have is obvious. The idol that wins the most competitions becomes the most invested in, is held in high regard by his company and is rewarded accordingly. Idols should be the ones to establish their own characters. Whatever character they want to portray should be made clear upon debut. Some idols start off with this in mind, but others prefer being ambiguous in order to capture a wider audience at the cost of losing their own identities. Their biggest "merit" is how they look, which means that appearance is what makes them an idol. The more components of their appearance can be sold to consumers, the higher rank they are deemed to have. Like a puppy, they are sold for their qualities and looks. They only get the chance to "win" and get what they want if they can please their masters. However, this is not an insult to idols. In a consumer-oriented idol industry, this is how it works. It's the nature of the beast that idols have to deal with when coming into an industry where money is involved in transactions between consumers and producers, big or small. This trend has transcended into both Japanese and Korean idol groups. For example, 
many argue that EXO was overrated when their group debuted because they had no real talent when compared to other rookies who put in more time at training centres.

Popularity, celebrityhood, and fan relationships are being digitized. The market economy has deeply impacted the fans' relationship with their idols as well as how they develop as individuals. This transition between passive and active roles has brought about a significant change in capital operation mode. After getting certain satisfaction in the material level, it is accompanied by people's higher requirements for spiritual consumption. With economic development and social progress, People's consumption needs are more diverse and have higher requirements. With the rapid development of wemedia, fan consumption culture breaks through the inherent single-mode and presents the characteristics of diversity. The virtuality and openness of "self-media" enrich people's identity, enabling fans to realize the free switch of identity and walk freely among different fan groups, becoming a veritable "nomad". Fay said in the interview: "I have three Weibo accounts that following different idols, and chats with people from different fans groups. Because they're like "competitive products", you have to show that idol is your only pick to get into the fandom group". Their emotional investment has led to a series of consumer behaviours and contributed to the rise of the fan economy. In the era of "we media", the rise of the fan economy is mainly reflected in two aspects: one is the rise of "fan movies". "Fan movie" is a new type of film which has emerged in China in recent years. It is a movie that is marketed by the popularity of stars. "Star + fan + movie + consumption" is the standard mode of "fan movie". On the surface, "fan movies" consume movies, but fundamentally, they consume fans' worship and support for stars. On the other hand, is the "FFC" model. With the advent of the era of "we Media", the fan economy has also experienced the transformation from content crowdsourcing and product crowdsourcing to "FFC" mode. "FFC" mode is a new business model with "factory + fans + customers" as standard. The core of Factory + Fans is that Fans become the axis of commercial communication, become the dominant force in the commercial economy to make large-scale product customization possible [4]. Unlike traditional idol worship in the past, today's idols involve various fields, and the emergence of "Social Media Celebrity", "Fostered idol" and other new idol groups; Finally, fans have diversified consumption methods. For example, in talent shows, fans can buy sponsored milk to vote or vote more by charging the VIP of the broadcasting platform.

The fan operation mechanism has also undergone a huge change. "Economic of Fandom" prevails investors take idol stars and their appendage as commodities, modern mass media as a means of communication, and "fans" as active receivers and producers, and obtain commodity profits and social benefits through the largescale market operation. The popularity of the fandom economy leads to the economic significance of consumer goods derived from the emotional output of fans' spiritual level. The ambiguity of the boundary between idol value choice and fans' power leads to the alienation of the relationship. It directly affects the ecology and order of the entire fan culture and entertainment environment. The data become the key indicators of idol influence. "Fans economy" can also be referred to as the carrying emotional "data economy," "fans group" are collected for integrating imagination, emotion, and interest relationship between the community. A self-operated economic model spawned by fans becomes more systematic, structural, organizational, and hierarchical. Unlike the universal "fandom economy," the fan-operated economy within the group does not include investors. "Self-operation" means that the members of a collective work in an orderly manner around a rule to complete their tasks, and do not interfere with each other, but also achieve self-growth. This mode of operation is more systematic, structured, organized, and hierarchical. There are even professional fans conducting public opinion guidance in the group, and professional anti-fans engaged in tarnishing the image of idols [5].

In this mode of operation, it is easier for fans to communicate with each other. They can post advice on Weibo and make suggestions to achieve common interests. For example, fans can suggest that their Fanclubs collectively buy concert tickets to get cheaper tickets. Besides, they can make friends through group chat because of their common interests. "In April, I went to Shanghai to watch the concert of my favourite idol group and visited Shanghai with the netizens I met in the fan group. I really like and enjoy making friends and traveling in this way, and sometimes I do not have the same free time to travel with my real-world friends.", Fay said. Nevertheless, this phenomenon has a bad influence on society. The criteria of an idol are based on his or her data and popularity so that it caused the emergence of false data. Data fraud occurs in the capital and fans of both groups. For example, the capital side manipulates data to let the designated person make to the group. The Mnet vote manipulation investigation is a 2019 South Korean entertainment scandal involving electoral fraud in several reality competition series produced and broadcast by the television channel Mnet [6]. While the fans would also increase data through improper means, such as buy a large amount of sponsored milk and even cause a large amount of milk waste, they also want to get the milk ticket to vote [7]. In addition, there can be conflicts between fan groups and aggressive behaviour, such as Internet rants. Some people spend too much of their parents' money or even take out loans to buy their idols' endorsed products [8]. Their professional skills are not solid enough for starts themselves, and most of them are quickly formed. Thus there will be falsetto and tone fixing when they have performances. At the same time, this will be too much emphasis on appearance level, aesthetic simplification, 
only through several lenses show themselves in the talent show, in this case, can only rely on superior appearance to attract the audience quickly, unlike traditional media, the generation of a star often need the blessing of masterpiece, will have a stable group of fans. Now, this depends on the appearance level of attraction of the fastpaced factory way of star-making cannot do. As a result, celebrities often fall apart, their fans lose, and their popularity goes as fast as it came. This model can meet the needs of profit-seeking capital operators but hindered the healthy development of the cultural industry. This kind of TV show provides more ordinary people on stage to become idols, but this is not screened by means of competition to have actual strength idols. More is the capital and program production group to the contestants packaging and marketing, with profit as the goal. It also has a negative impact on the value construction of underage fans [9].

The space for fans to interact with idols mainly lies in the network field. The continuous tracking of idols and the joint creation of good expectations of idols make individuals face the internal tension of weak subjectivity. Young people have been easily controlled by the immersive force of idol media, and their preferences have been manipulated. Therefore, the "bad influence" of idols on young people has already become an important issue in recent years. The attention of media on teenage fans often focuses on them being money-worshipping consumers. The idolization process is determined by idol production. Visual culture is manipulated by stars to explore the commercial value of fan communities under real-time control. With the increase in potential exchange value, some industry insiders have recognized that fans are a profitable object that can always be buffered by the network donation system. The capitals had created one set of immersive forces young individuals willing to dedicated to the success of idols, actively invest time and interaction, and money. Many young people spend a lot of time surfing the Internet every day on idols of all kinds of information, the formation of undesirable routines, and the decline in work efficiency and school performance. The network field is a space of asymmetric information, and rumours abound. Such a situation has made young people lose sight of the notion of 'public interest', When others' evaluation of their idols does not conform to their own cognition, some young people will fight back to defend their idols, causing endless conflicts such as abuse and doxing. It has also created a serious social problem that has brought psychological, physical, and social damage to young people's lives.

\section{CONCLUSION}

Charles H. Cooley indicated one's sense of self and self-esteem is built from others [10]. Due to the influence of idols, many fans will forget about their personal integrity and what they stand for. The craze that idol worshipping has created in China is scary because of the idol's overpowering presence. People usually lose themselves when they get caught up in a celebrity's life and forget about who they are and what their ordinary lives were like before an idol dominated them. Idol worship is becoming more popular in China because many idols are coming out of the country. This has caused the idol-worshipping subculture to grow because more people buy products that these idols sell or watch their movies and dramas than before. Also, media exposure is also a great blow to this subculture since there has been a large amount of attention on idols' private lives and their popularity both in China and abroad. This has sparked much more interest in idol worshipping among teenagers in China. In some cases, people may even change their personalities along with the fashionable style of their idol. It is a form of escapism that many of the idol's fans have used to get away from their everyday troubles. It is a way for people to forget about reality and concentrate on a different life that seems much more exciting. This may be because people want to reflect on their own lives and reflect on their failures. These celebrities are only a reflection of the society that they live in. As a result, they believe that a new life can be found by following an idol's lifestyle or becoming their friend. These intense feelings usually drive people to buy the idol's products, find out more about their private lives, or even give up their lives for the sake of their idols. When they idolize someone, a lot of people try to change their lives from what they are. They want to be like the stars in terms of style and behaviour, but if they did indeed adopt these kinds of lifestyles, their lives would not be as fun or interesting as they are now since the idol's style is not representative of any person's lifestyle.

\section{REFERENCES}

[1] E. Rogers, F. Shoemaker, n.d. Communication of innovations.

[2] Dengta APP, Taobao(China) Software CO.,LTD.

[3] H. Jenkins, (1992). Textual poachers. Routledge.

[4] Hanke Community: FFC Mode. Hanke.wang. (2021). Retrieved from http://www.hanke.wang/index.php? $\mathrm{m}=$ content\&c=i ndex $\& \mathrm{a}=$ show $\&$ catid $=18 \& \mathrm{id}=175$.

[5] H. Kruse, (1993). The Adoring Audience: Fan Culture and Popular Media. Edited by Lisa A. Lewis. London and New York: Routledge, 1992. 245 pp. Popular Music, 12(2), 205-206. https://doi.org/10.1017/s0261143000005638

[6] Vote-rigging suspicions undermine reputation of $\mathrm{K}$ pop audition shows - The Korea Times. Koreatimesus.com. (2019). Retrieved 6 November 2019, from http://www.koreatimesus.com/vote- 
rigging-suspicions-undermine-reputation-of-k-popaudition-shows/.

[7] "Daonai zhuixing"— "Qingchunyouni 3" has been stopped. Sohu.com. (2021). Retrieved from https://www.sohu.com/a/465047585_114988.

[8] G. Yuan, Lizhi Zhuixing Juzuo Jiucai, China Academic Journal Electronic Publishing House, 2021.

[9] Z. Zhen, Starchaser with reason, both for fans and idols. China Academic Journal Electronic Publishing House, 2021.

[10] C. Cooley, (1967). Human nature and the social order. Schocken. 